Gut, 1980, 21, 650-655

\title{
Possible role of a defect in hepatic bilirubin glucuronidation in the initiation of cholesterol gallstones
}

\author{
P DUVALDESTIN, J-L MAHU, J-M METREAU, JOSETTE ARONDEL, \\ ANNE-MARIE PREAUX, AND P BERTHELOT*
}

From the Unité de Recherches INSERM U-99, Hôpital Henri Mondor, Créteil, France

SUMMARY Abnormally low activity of hepatic bilirubin UDP-glucuronosyltransferase was found in $25 \%$ of 81 unselected patients with gallstones, as compared with only $3 \%$ in 35 controls. At the time of cholecystectomy, the stones were taken for analysis in 48 of 81 patients, and a bile sample was obtained in 42 of them. Among the stones, $75 \%$ were cholesterol stones, $15 \%$ pigment stones, and $10 \%$ 'intermediate' stones. Low hepatic conjugating activity was not preferentially associated with a given type of stone. No relation was found between the enzymic deficiency and the biliary cholesterol saturation index. A high proportion of biliary bilirubin monoglucuronide (over $40 \%$ ) was found in four of seven patients with low transferase activity, as was earlier demonstrated in patients with overt Gilbert's syndrome. Raised biliary bilirubin monoglucuronide was also found in three patients, out of 46 , who had normal transferase but raised biliary beta-glucuronidase activity. There was no evidence that deficient bilirubin conjugation could be a consequence of gallstones: the activity of another hepatic microsomal enzyme, glucose 6-phosphatase, taken as a reference, was measured in 12 patients and was always normal. Taking into account the very high frequency of a bilirubin centre in the cholesterol stones $(87 \%$ of the cases in the present series), it is suggested that the increased proportion in poorly soluble biliary bilirubin monoglucuronide, which was associated with defective conjugation, could act as a trigger for gallstone initiation, regardless of the final composition of the stone.

Considerable improvements in our knowledge of gallstone formation have been obtained during the last few years, when the role of so-called supersaturated bile in the pathogenesis of cholesterol gallstones $(\mathrm{CS})^{1-3}$ was proposed. In spite of this finding, however, several points remain obscure: (1) supersaturated bile may be observed in the absence of stones; ${ }^{4}(2)$ analysis of biliary cholesterol saturation after chenodeoxycholic acid therapy does not differentiate between patients in whom gallstones were dissolved and those in whom no dissolution occurred. ${ }^{5}$ In addition, it has been observed for years that 'pure cholesterol stones are rare: crystallisation seems to come from (or point towards) a centre at which a small amount of discolouration due to pigment may often be seen'. ${ }^{6}$ Conversely, it is of interest that the current definition

*Address for reprint requests: Pierre Berthelot, MD, Unité de Recherches INSERM U-99, Hôpital Henri Mondor, 94010 Créteil, France.

Received for publication 19 February 1980 of pigment stones (PS) does not take their absolute content of bilirubin into account. ${ }^{7}$ Alterations in bilirubin biotransformation could indeed contribute to stone formation and Black et al. ${ }^{8}$ have already shown that a low activity of hepatic bilirubin UDP-glucuronosyltransferase (B-GT) is a frequent finding in patients with gallstones. The ensuing increase in less soluble forms of biliary bilirubin, which occurs when the activity of B-GT is low, ${ }^{9}$ may play a role in the nucleation of the stones.

For all these reasons, it seemed of interest to re-examine the possible role of bilirubin metabolism and the biliary bilirubin composition in unselected patients with gallstones, using new techniques which permit the precise analysis of bilirubin. ${ }^{9}$

\section{Methods}

SUBJECTS

Eighty-one unselected patients with gallstones were studied. There were 20 males and 61 females; their 
age varied from 20 to 80 years (median: $47 \cdot 5$ years). Patients with obstructed cystic or common bile ducts, acute cholecystitis, or liver disease were excluded. None had overt haemolysis. Haemoglobin and serum levels of haptoglobin and bilirubin were normal in all cases. Apparently, no patient or control took any drug known to alter the activity of their liver microsomal enzymes. Thirty-five patients without known disease of the liver or of the biliary system acted as controls; they included 29 males and six females whose ages varied from 18 to 72 years (median: 47 years). Nutritional status was comparable in all the individuals included in the present study; they were all fasted for at least eight hours before the investigation. All the patients had given their informed consent before any procedure.

\section{SAMPLING PROCEDURES}

In both groups a liver biopsy was obtained and divided into two pieces, one for routine light microscopic examination and one for measurement of B-GT and glucose 6-phosphatase (see below). The liver sample was stored at $-20^{\circ} \mathrm{C}$ for a period which never exceeded two weeks; under such storage conditions, the enzyme activity was shown to remain constant for at least two months. ${ }^{10} \mathrm{~A}$ sample of tissue was obtained from a needle biopsy in 16 patients with gallstones before starting chenic acid therapy; at that time, in view of a possible toxicity of the drug, a biopsy was performed in all these cases. In 21 of the control patients, the biopsy was performed because of suspicion of liver disease, which was later ruled out because of the normal histological appearance. In 65 patients undergoing cholecystectomy and in 14 control patients operated on for peptic ulcer, a wedge liver sample was taken at time of surgery. Drugs used for premedication or anaesthesia consisted exclusively of non-inducing agents, apart from thiopental which was given shortly before the liver biopsy and would therefore not be expected to alter hepatic glucuronidation. In 50 of the patients undergoing cholecystectomy, all the stones were recovered for chemical analysis, and in 42 a sample of bile (gallbladder bile in 40 cases, common bile duct bile in the two cases of non-functioning gallbladder) was taken for bilirubin analysis and determination of the lithogenic index. It is known that there are no significant differences in bilirubin composition of gallbladder- (or duodenal-) vs. hepatic bile." The bile sample was immediately protected from light and frozen until examined.

CHEMICAL METHODS

B-GT was assayed in digitonin-activated liver homogenates $(5 \% \mathrm{w} / \mathrm{v})$ in $0.25 \mathrm{M}$ sucrose containing $1 \mathrm{mM}$ EDTA as previously described. ${ }^{1012}$ For convenie:ace the enzyme activity was expressed as $\mu \mathrm{mol}(\mathrm{mg})$ of bilirubin conjugated per hour and per gram of liver; the results were also calculated per milligram of liver protein. Abnormally low B-GT was defined as usual as activities below $1.20 \mu \mathrm{mol}(0.7 \mathrm{mg})$ of bilirubin conjugated $/ \mathrm{h} / \mathrm{g}$ of liver. ${ }^{1314}$ Glucose 6-phosphatase activity was measured in 12 homogenates (six with normal and six with low B-GT activity), according to the method described by Harper. ${ }^{15}$ This was done in order to eliminate a non-specific alteration in microsomal enzymes due either to sampling and storage conditions or to the underlying disease itself.

In the stones, cholesterol and bilirubin content was measured. The gallstones were washed with distilled water and wiped. Before analysis, their appearance was recorded by visual inspection on cross-section. The stones were then pulverised and dried to constant weight. An aliquot of the gallstone powder was extracted in isopropanol for 15 minutes. Cholesterol was measured in the isopropanol extract by the enzymic method of Roeschlau et al. ${ }^{16}$ For bilirubin measurement $5 \mathrm{mg}$ of the pulverised sample were extracted with a chloroform-methanol $(2: 1, \mathrm{v} / \mathrm{v})$ solution containing $1 \%$ of $1 \mathrm{~N} \mathrm{HCl}{ }^{17}$ The portion of powdered stone which was insoluble in acid chloroform-methanol was dried, weighed, and designated the residue. One millilitre of the extract was added to $2 \mathrm{ml}$ acetoneethanol $(1: 1, \mathrm{v} / \mathrm{v})$ mixture and incubated for 60 minutes at $0 \mathrm{C}$ with diazotized p-iodoaniline; ${ }^{18}$ $3 \mathrm{ml}$ of a solution of ascorbic acid $(1 \% \mathrm{w} / \mathrm{v}$ in $0.1 \mathrm{M} \mathrm{NaCl}$ ) were added to stop the reaction; the tubes were centrifuged and the azopigments measured in the lower phase at $530 \mathrm{~nm}$. Bilirubin concentration ( $\mu \mathrm{g}$ of bilirubin per mg of dry weight) was calculated from $\mathrm{A}_{530}^{1 \mathrm{~cm}} \times 25.6 \times 0.64$, where $25 \cdot 6$ was the extinction coefficient obtained from a calibration curve and 0.64 corresponded to the volume of the lower phase obtained at the end of the reaction. It was verified by thin layer chromatography (TLC) ${ }^{11}$ that the bilirubin in the stones was exclusively the non-conjugated pigment.

Bile samples were treated with diazotized ethylanthranilate followed by TLC. ${ }^{9}$ On such treatment, azopigments will separate mainly into unconjugated $\left(\right.$ alpha $\left._{0}\right)$ and glucuronidated (delta) azodipyrroles. This method thus allows the respective proportions of mono- and diglucuronide to be calculated from

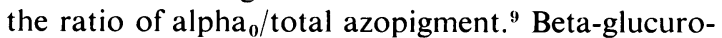
nidase activity was assayed in the bile of 44 patients with phenolphthalein glucuronide as substrate ${ }^{19}$ and incubation at $\mathrm{pH} 6.8$ in order to measure mainly the bacterial enzyme. The lowest activity 
that could be accurately measured was $48 \mathrm{nmol}$ $(15 \mu \mathrm{g})$ of phenolphthalein formed per $\mathrm{h} / \mathrm{ml}$.

In order to determine cholesterol saturation, the following measurements were made in aliquots of gallbladder bile: cholesterol, by the enzymic method of Roeschlau et al., ${ }^{16}$ phospholipids by the method of Bartlett, ${ }^{20}$ and total bile salts by an enzymic method using 3 alpha-hydroxysteroiddehydrogenase as previously described. ${ }^{2122}$ The lithogenic index was calculated according to the equation proposed by Thomas and Hofmann, ${ }^{23}$ using the maximal cholesterol solubility as proposed by Holzbach et al. ${ }^{4}$ Statistical analysis was carried out by determining the mean \pm SEM for each parameter studied in each group and applying the standard Student's unpaired $t$ test or the $\chi^{2}$ test for two independent variables between groups. ${ }^{24}$

\section{Results}

\section{HEPATIC B-GT}

No significant difference was observed when B-GT activity was assayed from a needle or from a surgical biopsy: the mean values were $2 \cdot 18 \pm 0 \cdot 17$ (SEM) $\mu \mathrm{mol}(1.28 \pm 0.10 \mathrm{mg}) \mathrm{per} \mathrm{h} / \mathrm{g}$ liver in the former and $2.30 \pm 0.20(1.35 \pm 0.12)$ in the latter. The results were therefore combined, giving for the controls a mean B-GT of $2 \cdot 24 \pm 0.13 \mu \mathrm{mol}(1 \cdot 31 \pm 0.08 \mathrm{mg})$ per $\mathrm{h} / \mathrm{g}$. Among the 35 controls there was only one who had a low B-GT $(0.46 \mu \mathrm{mol}(0.27 \mathrm{mg})$ per $\mathrm{h} / \mathrm{g})$. This finding contrasted with the 81 patients having gallstones, 20 of whom had a low B-GT $(\mathrm{P}<0.01)$. The activities in these 20 patients exhibited a mean of $0.71 \pm 0.05 \mu \mathrm{mol}(0.42 \pm 0.03 \mathrm{mg})$ per $\mathrm{h} / \mathrm{g}$, the values ranging from 0.20 to $1.04 \mu \mathrm{mol}(0.12$ to $0.61 \mathrm{mg}$ ) per $\mathrm{h} / \mathrm{g}$. The presence of patients with low B-GT did not significantly influence the mean value observed in the group of patients with gallstones, which was $1.99 \pm 0.12 \mu \mathrm{mol}(1.17 \pm 0.07 \mathrm{mg})$ per h/g.

In patients with gallstones, the B-GT deficiency occurred in $30 \%$ of the males, compared with $23 \%$ of the females; this difference, however, was not significant. Whereas in the females a similar frequency of low B-GT was noted regardless of the age, such deficiency seemed more frequent in males under 45 years of age $(45 \%)$ than among those who were aged over 45 years $(11 \%)$. However, this difference was not statistically significant.

\section{STONE COMPOSITION}

In 50 cases the cholesterol and bilirubin content of the gallstones was measured. Thirty-eight patients had a cholesterol content higher than $75 \%$ of the dry weight and were therefore considered as having cholesterol gallstones; they included seven males and 31 females. Macroscopically the cross-section
Table 1 Hepatic bilirubin UDP-glucuronosyltransferase $(B-G T)$ activity in patients having cholesterol- (CS), pigment- (PS), or intermediate stones (IS)

\begin{tabular}{|c|c|c|c|}
\hline \multirow[t]{2}{*}{ Type of stone } & \multirow[t]{2}{*}{$B-G T^{*}$} & \multicolumn{2}{|c|}{ Patients with low B-GT+ } \\
\hline & & (n) & $(\%)$ \\
\hline $\begin{array}{l}\text { CS } \\
(n=34) \\
\text { PS } \\
(n=7) \\
\text { IS } \\
(n=5)\end{array}$ & $\begin{array}{c:c}2.12 & 0.15 \\
(1.24 & 0.09) \\
2.17 & 0.46 \\
(1.27 & 0.27) \\
2.72 & 0.68 \\
(1.59 & 0.40)\end{array}$ & 0 & $\begin{array}{l}16 \\
14\end{array}$ \\
\hline
\end{tabular}

*B-GT is expressed as $\mu \mathrm{mol}(\mathrm{mg})$ of bilirubin conjugated per $\mathrm{h} / \mathrm{g}$ of liver (mean \pm SEM).

†Low B-GT was defined as activity below $1.20 \mu \mathrm{mol}(0.70 \mathrm{mg})$ per $\mathrm{h} / \mathrm{g}$.

Table 2 Stone composition in 50 cases of cholesterol- (CS), pigment- (PS), or intermediate stones (IS)

\begin{tabular}{lrrl}
\hline & Cholesterol* $^{*}$ & \multicolumn{1}{c}{ Bilirubin* $^{*}$} & \multicolumn{1}{c}{ Residue* } \\
\hline $\begin{array}{l}\text { CS } \\
(\mathrm{n}-38)\end{array}$ & $98.08 \pm 2.61$ & $1.39 \pm 0.20$ & $0.17+0.12$ \\
$\begin{array}{l}\mathrm{PS} \\
(\mathrm{n}=7)\end{array}$ & $6.47 \pm 2.46$ & $19.56 \pm 8.10$ & $32.24 \pm 6.02 \dagger$ \\
$\begin{array}{l}\text { IS } \\
(\mathrm{n}=5)\end{array}$ & $53.52 \pm 5.21$ & $9.57 \pm 8.58$ & nil $\dagger$ \\
\hline
\end{tabular}

*Expressed as percentage of the dry weight (mean \pm SEM).

†Addition of the three parameters measured did not reach $100 \%$; these therefore do not reflect all possible constituents?of these types of stones, as previously observed by Nakayama. ${ }^{17}$ The high also reflects the presence of unidentified, amorphous, material in the PS.

showed a pigment centre in $\mathbf{3 3}$ of the 38 cholesterol gallstones $(87 \%)$. Seven patients had pigment stones, defined on the basis of a cholesterol content lower than $25 \% ;^{2}$ they were three males and four females. Five patients, all females, had intermediate stones (IS). B-GT was measured in 46 of 50 patients. There was no significant difference in B-GT distribution according to the type of the gallstone (Table 1). Low B-GT was observed in six patients with cholesterol gallstones, in one with pigment stones, and in none of the five with intermediate stones. Bilirubin accounted for $19 \cdot 6,1 \cdot 3$, and $9 \cdot 6 \%$ of the dry weight of PS, CS, and IS, respectively (Table 2). In addition, in six unselected CS having a dark centre, bilirubin content was measured separately in the centre and at the periphery. In each case, bilirubin content was much higher in the centre, with a mean concentration ratio of 7.5 (values ranging from $2 \cdot 2$ to $19 \cdot 5$ ).

\section{BILIARY BILIRUBIN}

The composition of the bile was assessed in 42 patients, 30 with CS, seven with PS, and five with IS. A bilirubin monoglucuronide/total conjugates ratio equal to, or higher than $40 \%$ was found in 
nine patients (Table 3). In seven of them, such a high proportion of bilirubin monoglucuronide appeared to be a consequence of either a low B-GT (four cases), ${ }^{9}$ or a beta-glucuronidase activity exceeding $318 \mathrm{nmol}(100 \mu \mathrm{g}) \mathrm{per} \mathrm{h} / \mathrm{ml}$ (three cases), compared with $48 \pm 4 \cdot 2(15 \pm 1 \cdot 3)$ in the remaining patients. In the two patients whose percentages of bilirubin monoglucuronide/total conjugates were slightly raised (43.6 and 41.4$)$ in spite of a normal B-GT $(2.60$ and $4.19 \mu \mathrm{mol}(1.52$ and $2.45 \mathrm{mg})$ of bilirubin conjugated per $\mathrm{h} / \mathrm{g}$, respectively, and almost undectable beta-glucuronidase activity 48 and $64 \mathrm{nmol}(15$ and $20 \mu \mathrm{g}) \mathrm{per} \mathrm{h} / \mathrm{ml}$ respectively), no explanation was found. When the seven patients with either a low B-GT or a biliary beta-glucuronidase activity greater than $318 \mathrm{nmol}(100 \mu \mathrm{g})$ per $\mathrm{h} / \mathrm{ml}$ were excluded, then the mean percentage of bilirubin monoglucuronide was $31.6 \%$ in the group of CS, $27.4 \%$ in that of PS, and $29.0 \%$ in that of IS. These three values are all of the same order of magnitude as the mean value $(27 \cdot 2 \pm 7 \cdot 8 \%)$ that we found previously in healthy individuals. ${ }^{9}$

Among the five patients having $40 \%$ or more bilirubin monoglucuronide, there were two CS, two PS, and one IS; there was no obvious relation between the bilirubin monoglucuronide content and the chemical type of the stones.

\section{LITHOGENIC INDEX}

The mean lithogenic index was determined in the bile of 40 patients. It was of course higher in the 29 patients with CS than in the seven having PS (Table 4). Among the patients with CS, the lithogenic index of the six with low B-GT activity did not differ from that observed in the 25 individuals with normal enzymic activity. Nor did the lithogenic index of the single PS patient having low B-GT activity differ from that of the other six individuals.
Table 4 Mean lithogenic index in the bile of patients having cholesterol- (CS) or pigment stones (PS) according to hepatic bilirubin UDP-glucuronosyltransferase (B-GT) activity

\begin{tabular}{|c|c|c|c|}
\hline \multirow[t]{2}{*}{ Type of stone } & \multicolumn{2}{|c|}{$\begin{array}{l}\text { Mean lithogenic index* } \\
\text { ( } n \text { of patients) }\end{array}$} & \multirow[b]{2}{*}{$\begin{array}{l}\text { Withlow } \\
B-G T \ddagger\end{array}$} \\
\hline & All & $\begin{array}{l}\text { With normal } \\
B-G T \dagger\end{array}$ & \\
\hline CS & $\begin{array}{l}1.36 \pm 0.08 \\
(29)\end{array}$ & $\begin{array}{l}1.38+0.09 \\
(23)\end{array}$ & $\begin{array}{l}1.31 \pm 0.08 \\
\text { (6) }\end{array}$ \\
\hline PS & $\begin{array}{l}0 \cdot 76 \pm 0 \cdot 03 \\
(7)\end{array}$ & $\begin{array}{l}0 \cdot 76 \pm 0.04 \\
(6)\end{array}$ & $\begin{array}{l}0 \cdot 75 \\
(1)\end{array}$ \\
\hline
\end{tabular}

*Lithogenic index \pm SEM was calculated from the equation given by Thomas and Hofmann. ${ }^{23}$

$\nmid \mathrm{B}-\mathrm{GT}$ is expressed as $\mu \mathrm{mol}(\mathrm{mg})$ of bilirubin conjugated per $\mathrm{h} / \mathrm{g}$ of liver \pm SEM.

$\ddagger$ Low B-GT was defined as activity below $1.20 \mu \mathrm{mol}(0.70 \mathrm{mg}$ per $\mathrm{h} / \mathrm{g}$.

\section{GLUCOSE 6-PHOSPHATASE}

There were no significant differences between the values of glucose 6-phosphatase activity in six patients with and six without low B-GT: $74 \cdot 1$ 上 $3.1 \mathrm{nmol}$ per $\mathrm{min} / \mathrm{mg}$ protein and $72.6 \pm 1 \cdot 7$, respectively.

\section{Discussion}

In the present series, 20 out of the 81 patients with gallstones had a low B-GT activity. A similar finding has already been made by Black et al. ${ }^{8}$ who found five cases with enzymic deficiency among 34 patients undergoing cholecystectomy for cholelithiasis. In contrast, such a defect existed in only one of our 35 controls, and in one of 26 of the patients of Black et al. ${ }^{8}$ who were operated on for causes other than biliary lithiasis. The lowest limit of 'normal' B-GT activity is difficult to assess, and it has been arbitrarily fixed at $1.20 \mu \mathrm{mol}$

Table 3 Chemical type of stones, hepatic bilirubin UDP-glucuronosyltransferase (B-GT) activity, and biliary bacterial beta-glucuronidase activity in nine patients with high bilirubin monoglucuronide content in bile

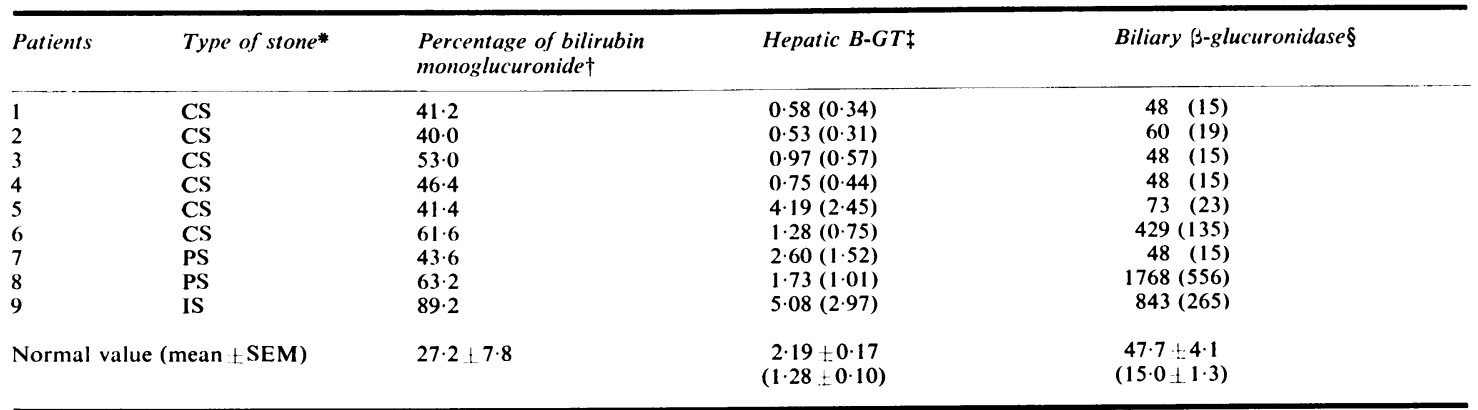

*Cholesterol- (CS), pigment- (PS), or intermediate stones (IS) as defined from their cholesterol content. ${ }^{\text {* }}$

†Calculated from the $\alpha_{0}$-azopigment-that is, the unconjugated azodipyrrole, formed from coupling with diazotized ethylanthranilate. ${ }^{\circ}$

$\ddagger$ B-GT is expressed as $\mu \mathrm{mol}(\mathrm{mg})$ of bilirubin conjugated per $\mathrm{h} / \mathrm{g}$ of liver.

$\S(3-$ glucuronidase activity is expressed as nmol $(\mu \mathrm{g})$ of phenolphthalein formed $\mathrm{per} \mathrm{h} / \mathrm{ml}$ bile. 
$(0.7 \mathrm{mg})$ per $\mathrm{h} / \mathrm{g}$ liver. It is of interest that the mean B-GT activity in the 20 patients with gallstones who had low levels of transferase was significantly higher than the activity we observed in a group of 37 adults patients with overt Gilbert's syndrome: ${ }^{14}$ the means were $0.72 \pm 0.05 \mu \mathrm{mol}(0.42 \pm 0.03 \mathrm{mg})$ per $\mathrm{h} / \mathrm{g}$ and $0.43+0.05(0.25+0.03)$, respectively $(P<0.001)$. This strongly suggests that, although B-GT was reduced in both groups, they both represent different degrees of a common biochemical defect. In accordance with such a hypothesis, it should be noticed that among our subjects with B-GT deficiency (20 with cholelithiasis and one control), none had an unconjugated hyperbilirubinaemia. Similarly, the B-GT deficiency found recently by Felsher and Carpio ${ }^{25}$ in chronic persistent hepatitis was comparable with that of our 20 patients in those who had normal serum bilirubin, whereas the enzymic activity was as low as in Gilbert's syndrome when unconjugated hyperbilirubinaemia was present.

The B-GT deficiency was a slightly more frequent finding in males aged under 45 years, whereas cholelithiasis affects predominantly women who are over 45 years; however, probably in view of the relatively small number of males who were investigated, this was not significant. In contrast with the patients with gallstones, our control group predominantly consisted of males. None of the previously published series of B-GT measurements in man have ever mentioned any sex differences. Our own results, although dealing with only six female controls, also failed to suggest any significant sex-linked difference in the normal hepatic B-GT activity: $2.14 \pm 0.21 \mu \mathrm{mol}(1.25 \pm 0.13 \mathrm{mg})$ per $\mathrm{h} / \mathrm{g}$ in the females and $2.26+0.15(1.32 \div 0.09)$ in the males.

Three main explanations for the association between a low B-GT activity and the presence of gallstones can be offered. Firstly, fortuitous coincidence; this however appears to be unlikely because of the statistical significance which existed for the low B-GT activity in our series compared with normal subjects as well as the frequency of the enzymic defect observed in the patients of Black et al. $^{8}$ Secondly, there is no evidence to support the hypothesis that cholelithiasis caused the low B-GT activity. If this were the case, one would expect that the enzymic deficiency would be found more frequently and be associated with other microsomal enzymic defects. This latter possibility was ruled out because the glucose 6-phosphatase activity was similar in patients with or without B-GT deficiency. For these reasons, it is more tempting to speculate that B-GT deficiency played a role in the formation of gallstones. In this regard, it is of interest that no clear relation could be found between B-GT deficiency and the composition of the stones. Such an enzymic deficiency was encountered as frequently in cholesterol gallstones as in pigment stones, which suggests that the B-GT deficiency favoured the formation of both types of stones. This obviously was not the result of the influence of B-GT on biliary cholesterol saturation. In fact, $16 \%$ of our patients with CS had a lithogenic index of 1.00 or less, thus indicating that cholesterol supersaturation is not always the cause of CS formation.

Abnormal bilirubin metabolism could be responsible for the initiation of CS, especially bearing in mind the fact that $87 \%$ of the CS of the present series had a bilirubin centre. Biliary unconjugated bilirubin should, however, not be implicated for the following reasons: (1) only very small amounts of this pigment exist in bile (approximately 1\% total), which cannot be simply related to the biliary deconjugating activity ${ }^{26}{ }^{2}(2)$ when we analysed the bile of numerous adults with low hepatic B-GT activity, no increase in biliary unconjugated bilirubin was found. ${ }^{9}$

An increase in the proportion of biliary monoglucuronide could offer a reasonable explanation for gallstone formation, as it is less water-soluble than the diglucuronide which normally predominates in human bile. ${ }^{11}$ At present, two main causes are known to produce an increased proportion of bilirubin monoglucuronide in bile. The first is a raised biliary bacterial beta-glucuronidase activity; this was observed in three instances in this work, although it must be remembered that deconjugation of phenolphthalein does not necessarily reflect that of bilirubin. The second, as we have shown in previous work, is B-GT deficiency, which is very frequently associated with a high proportion of biliary bilirubin monoglucuronide. ${ }^{9}$

It should, however, be noted that the frequency of a bilirubin centre in our cholesterol stones seems to far exceed that of patients having conjugation deficiency. Moreover, in Gilbert's syndrome, although an increased incidence of gallstones has been suggested ${ }^{27}$ convincing evidence needs to be obtained from a prospective, controlled study. Nevertheless, it remains tempting to speculate that decreased B-GT activity may contribute to gallstone formation, whatever their type, via an increase in biliary bilirubin monoglucuronide. Such a hypothesis is not invalidated by the limited number of cases in which we found raised biliary monoglucuronide values. The measured B-GT and biliary composition may well be only a poor reflection of more important alterations which existed at the time of stone nucleation. Even though of brief 
duration, an increased proportion of biliary monoglucuronide could act as a trigger for stone initiation in a given saturation biliary cholesterol, but different bile nucleation times. ${ }^{28}$

This study was supported by grants from the Institut National de la Santé et de la Recherche Médicale (INSERM) and the University Paris XII. The authors wish to thank Professor R $\mathrm{H}$ Dowling and Dr G E Murphy for their most stimulating discussion; Drs J Chapman, D Dhumeaux, S Erlinger, J Hanoune, and B Vicking for constructive advice or help, and Mrs M Tassier and Miss C Petit for the care they took while preparing the manuscript.

\section{References}

'Danzinger RG, Hofmann AF, Thistle JL, Schoenfield LJ. Effect of oral chenodeoxycholic acid on bile acid kinetics and biliary lipid composition in women with cholelithiasis. J Clin Invest 1973; 52: 2809-21.

${ }^{2}$ Iser JH, Dowling RH, Mok HYI, Bell GD. Chenodeoxycholic acid treatment of gallstones. A follow-up report and analysis of factors influencing response to therapy. N Engl J Med 1975; 293: 378-83.

${ }^{3}$ Carey MC, Small DM. The physical chemistry of cholesterol solubility in bile. Relationship to gallstone formation and dissolution in man. J Clin Invest 1978; 61: 998-1026.

${ }^{4}$ Holzbach RT, Marsh M, Olszewski M, Holan K. Cholesterol solubility in bile. Evidence that supersaturated bile is frequent in healthy man. $J$ Clin Invest 1973; 52: 1467-79.

${ }^{5}$ Bateson MC, Ross PE, Murison J, Bouchier IAD. Comparison of fixed doses of chenodeoxycholic acid for gallstone dissolution. Lancet 1978; 1: 1111-4.

${ }^{6}$ Rains AJH. Gallstones: causes and treatment, London: Heinemann, 1964: 11-20.

${ }^{7}$ Soloway RD, Trotman BW, Ostrow JD. Pigment gallstones. Gastroenterology 1977; 72: 167-82.

${ }^{8}$ Black M, Perrett RD, Carter AE. Hepatic bilirubin UDP-glucuronyl transferase activity and cytochrome $\mathbf{P}_{450}$ content in a surgical population, and the effects of preoperative drug therapy. J Lab Clin Med 1973; 81: 704-12.

${ }^{9}$ Fevery J, Blanckaert N, Heirwegh KPM, Preaux AM, Berthelot P. Unconjugated bilirubin and an increased proportion of monoconjugates in the bile of patients with Gilbert's syndrome and Crigler-Najjar disease. J Clin Invest 1977; 60: 970-9.

${ }^{10}$ Duvaldestin P, Mahu JL, Berthelot P. Effect of fasting on substrate specificity of rat liver UDP-glucuronosyltransferase. Biochim Biophys Acta 1975; 384: 81-6. ${ }^{11}$ Fevery J, Van Damme B, Michiels R, De Groote J, Heirwegh KPM. Bilirubin conjugates in bile of man and rat in the normal state and in liver disease. $J$ Clin Invest 1972; 51: 2482-92.

${ }^{12}$ Black M, Billing BH, Heirwegh KPM. Determination of bilirubin UDP-glucuronyl transferase activity in needle-biopsy specimens of human liver. Clin Chim Acta 1970; 29: 27-35.

${ }^{13}$ Black M, Billing BH. Hepatic bilirubin UDP-glucuronyltranferase activity in liver disease and Gilbert's syndrome. $N$ Engl J Med 1969; 280: 1266-71.

${ }^{14}$ Metreau JM, Yvart J, Dhumeaux D, Berthelot P. Role of bilirubin overproduction in revealing Gilbert's syndrome: is dyserythropoiesis an important factor? Gut 1978; 19: 838-43.

${ }^{15}$ Harper AE. Glucose-6-phosphatase. In: Bergmeyer HU, ed. Methods of enzymatic analysis, Weinheim: Verlag Chemie, 1963; 788-92.

${ }^{16}$ Roeschlau P, Bernt E, Gruber W. Enzymatische Bestimmung des Gesamt-Cholesterins im Serum. Z Klin Chem Klin Biochem 1974; 12: 403-7.

${ }^{17}$ Nakayama F. Quantitative microanalysis of gallstones. $J$ Lab Clin Med 1968; 72: 602-11.

${ }^{18}$ Van Roy FP, Meuwissen JATP, De Meuter F, Heirwegh KPM. Determination of bilirubin in liver homogenates and serum with diazotized p-iodo aniline. Clin Chim Acta 1971; 31 : 109-18.

${ }^{19}$ Rodriguez Garay EA, del Rosario Spetale M, Morisoli LS. Relationship between bilirubin and $\beta$-glucuronidase activity in rats with experimental obstructive jaundice. Clin Chim Acta 1972; 37: 171-7.

${ }^{20}$ Bartlett GR. Phosphorus assay in column chromatography. J Biol Chem 1959; 234: 466-8.

${ }^{21}$ Berthelot P, Erlinger S, Dhumeaux D, Préaux AM. Mechanism of phenobarbital-induced hypercholeresis in the rat. Am J Physiol 1970; 219: 809-13.

${ }^{22}$ Mahu JL, Duvaldestin P, Dhumeaux D, Berthelot P. Biliary transport of cholephilic dyes: evidence for two different pathways. Am J Physiol 1977; 232: E445-50.

${ }^{23}$ Thomas PJ, Hofmann AF. A simple calculation of the lithogenic index of bile: expressing biliary lipid composition on rectangular coordinates. (Letter) Gastroenterology 1973; 65: 698-700.

${ }^{24}$ Siegel S. Nonparametric statistics for the behavioral sciences. New York: McGraw-Hill, 1956: 104-11.

${ }^{25}$ Felsher BF, Carpio NM. Chronic persistent hepatitis and unconjugated hyperbilirubinemia. Gastroenterology 1979; 76: 248-52.

${ }^{26}$ Boonyapisit ST, Trotman BW, Ostrow JD. Unconjugated bilirubin, and the hydrolysis of conjugated bilirubin, in gallbladder bile of patients with cholelithiasis. Gastroenterology 1978; 74: 70-4.

${ }^{27}$ Foulk WT, Butt HR, Owen CA Jr, Whitcomb FF Jr, Mason HL. Constitutional hepatic dysfunction (Gilbert's disease): its natural history and related syndromes. Medicine (Baltimore) 1959; 38: 25-46. ${ }^{28}$ Holan KR, Holzbach RT, Hermann RE, Cooperman AM, Claffey WJ. Nucleation time: a key factor in the pathogenesis of cholesterol gallstone disease. Gastroenterology 1979; 77: 611-7. 